\title{
Pengembangan Kemampuan Enterpreneur Sebagai Upaya Meningkatkan Competitive Advantage UMKM
}

\author{
Ratna Ekasari*, Setiawan, Anita Wulandari, Wahyu Kunsiati, Mariyana Novitasari \\ Fakultas Ekonomi dan Bisnis, Universitas Maarif Hasyim Latif, Jalan Ngelom Megare, Sidoarjo, Indonesia, \\ 61257
}

Correspondence: ratna_ekasari@dosen.umaha.ac.id Received: 30 Juni 2021 - Revised: 01 Agustus 2021 - Accepted: 16 Agustus 2021

\begin{abstract}
Abstrak. Dalam rangka mengembangkan kemampuan entrepreneur untuk meningkatkan daya saing melalui UMKM, maka Universitas Maarif Hasyim Latif memberikan bekal tambahan bagi pengusaha kecil dan menengah untuk menghadapi persaingan di dunia usaha. Salah satu usaha yang dilakukan adalah melalui penyuluhan cara pembuatan laporan keuangan yang benar. Program ini dilaksanakan melalui pendampingan tentang pembuatan laporan keuangan (Laporan Laba Rugi, Laporan Perubahan Modal, Neraca, Laporan Arus Kas, dan Catatan atas Laporan Keuangan) dengan tujuan untuk mengembangkan UMKM agar mampu bersaing dalam dunia usaha di pasar nasional. Berdasarkan pengamatan dari 7 UMKM yang ada, hampir $85 \%$ belum bisa membuat laporan keuangan. Sedangkan pengelolaan keuangan hanya berdasarkan pemasukan dan pengeluaran tanpa ada pemisahan antara modal usaha dan modal pribadi.
\end{abstract}

Kata kunci: UMKM, enterpreneur, competitive advantage

Citation Format: Ekasari R., Setiawan, Wulandari, A., Kunsiati, W., \& Novitasari, M.. (2021). Pengembangan Kemampuan Enterpreneur Sebagai Upaya Meningkatkan Competitive Advantage UMKM. Prosiding Seminar Nasional Abdimas Ma Chung (SENAM), 380-386. 


\section{PENDAHULUAN}

Tahun 1997 adalah tahun kritis bagi Indonesia karena terpuruknya nilai tukar rupiah terhadap dollar AS. Dampak krisis moneter juga berpengaruh pada perekonomian Indonesia yaitu resesi ekonomi. Inilah momen penting bagi Indonesia untuk memiliki struktur yang kuat dan dapat bertahan dalam situasi apapun termasuk dalam bidang perekonomian (Anggraini \& Nasution, 2013). Meski krisis ekonimi terjadi, ternyata UMKM (Usaha Mikro Kecil dan Menengah) masih mampu bertahan. Data BPS (Badan Pusat Stastistik) menyatakan bahwa jumlah UMKM tidak berkurang pasca krisis, pada kenyataannya makin meningkat yang bahkan menyerap 85 juta hingga 107 juta tenaga kerja.

Ini menunjukkan bahwa UMKM merupakan usaha yang produktif untuk dikembang kan bagi mendukung perkembangan ekonomi secara makro dan mikro di Indonesia dan mempengaruhi sektor-sektor yang lain bisa berkembang. Sektor perbankan terpengaruh krisis ekonomi karena hampir 30\% UMKM memakai modal operasional dari jasa perbankan. Minimnya modal, tidak adanya kemampuan manajerial, kurangnya jaringan pemasaran adalah kelemahan yang dihadapi UMKM (Suci, 2017).

Desa Tanjungan Kecamatan Driyorejo merupakan desa yang berpenduduk sekitar 5000 jiwa selalu berbenah dalam bidang pembangunan, baik infra struktur maupun ekstra struktur,yang dibiayai dari dana pemerintah,swadaya warga dan juga dana pribadi dari kepala desa. Disamping pembangunan fisik, peningkatan Sumber Daya Manusia (SDM), pertanian, Usaha Mikro Kecil dan Menengah (UMKM) dan pelayanan prima juga menjadi prioritas untuk dilakukan pengembangan. Bersinergi dengan program desa dalam peningkatan dan pemberdayaan UMKM di Desa Tanjungan, maka kegiatan KKN Tematik - KK ini dilakukan.

Permasalahan utama dalam pengelolaan UMKM adalah mayoritas karena permodalan, manajerial, dan pemasaran. Menurut (Narsa, Widodo, \& Kurnianto, 2012) kendala utama yang dihadapi pihak UMKM selain modal adalah penerapan manajemen yang profesional. UMKM juga menghadapi keterbatasan modal, rendahnya sumber daya yang ada, serta penguasaan terhadap teknologi dan ilmu pengetahuan sangat rendah (S. Sudaryanto \& Hanim, 2002). Oleh karena itu, adanya kemudahan akses informasi dan jaringan pasar, kemudahan akses pendanaan dan pendampingan serta peningkatan 
kapasitas teknologi informasi merupakan beberapa strategi peningkatan daya saing UMKM Indonesia (R. Sudaryanto \& Wijayanti, 2013).

Kegiatan ini dalam rangka meningkatkan kemampuan enterpreneur yang dilaksanakan di Desa Tanjungan diharapkan mampu meningkatkan daya saing UMKM di pasar lokal maupun nasional dalam rangka peningkatan perekonomian kerakyatan.

\section{MASALAH}

UMKM mempunyai masalah yang sangat penting yang berkaitan dengan keuangan yaitumodal. Pada saat UMKM ingin mengajukan permohonan bantuan keuangan kepada perbankan, maka UMKM sangat diwajibkan menjadi bankable. Bankable merupakan slaah satu permasalahan yang dihadapi UMKM. Oleh sebab itu, melalui kegiatan pengabdian ini diharapkan UMKM dapat menjadi bankable terutama untuk pembuatan laporan keuangan UMKM.

\section{METODE PELAKSANAAN}

Kegiatan ini dilaksanakan di Desa Tanjungan, Kecamatan Driyorejo, Kabupaten Sidoarjo dengan mengamati beberapa pemilik UMKM di desa tersebut, yang berjumlah 7 UMKM dari berbagai jenis bidang usaha. Metode yang digunakan adalah metode penyuluhan dan pelatihan berupa ceramah atau penyuluhan atau sosialisasi tentang tata cara pembuatan laporan keuangan. Pelatihan juga dilakukan terkait pengelolaan keuangan dan cara pembukuan secara sederhana.

\section{HASIL DAN PEMBAHASAN}

Kegiatan penyuluhan dan pelatihan pembukuan tentang UMKM ini meliputi pelatihan pengelolaan pembukuan keuangan. Foto kegiatan dapat dilihat di gambar 1, gambar 2, dan gambar 3.

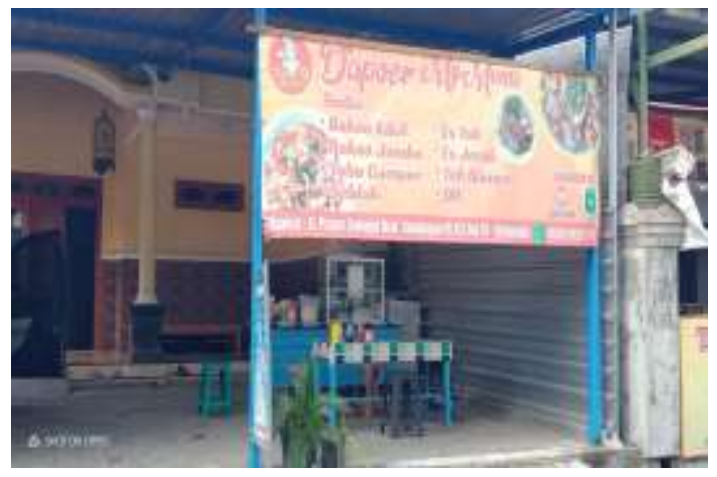

Gambar 1. Penyuluhan tentang pembuatan laporan keuangan kepada pemilik UMKM di Desa Tanjungan 


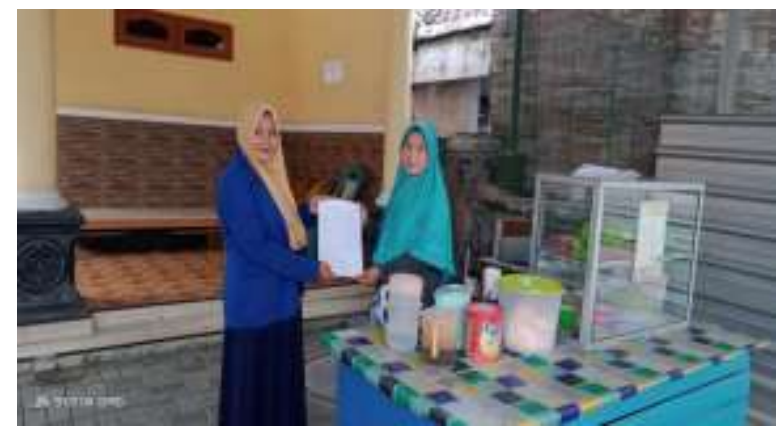

Gambar 2. Pelatihan tentang pembuatan laporan keuangan kepada pemilik UMKM di Desa Tanjungan

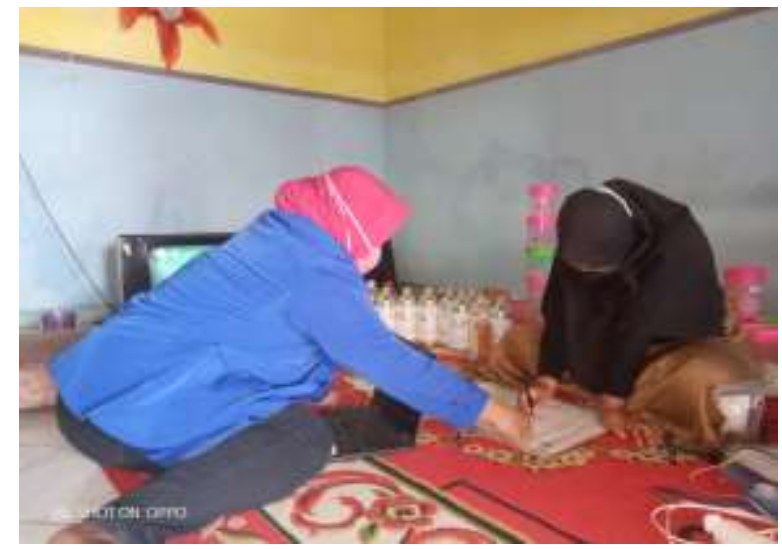

Gambar 3. Pelatihan tentang pembuatan laporan keuangan kepada pemilik UMKM di Desa Tanjungan

Berdasarkan hasil pengamatan data terkait jenis UMKM dari pelaku usaha di Desa Tanjungan dapat dilihat pada tabel 1 .

Tabel 1. Jenis bidang usaha UMKM Desa Tanjungan

\begin{tabular}{lll}
\hline No. & Bidang usaha & Jumlah \\
\hline 1 & Makanan dan minuman & 4 \\
2 & Toko kelontong & 3 \\
\hline & Jumlah & 7 \\
\hline
\end{tabular}




\section{Bidang usaha UMKM}

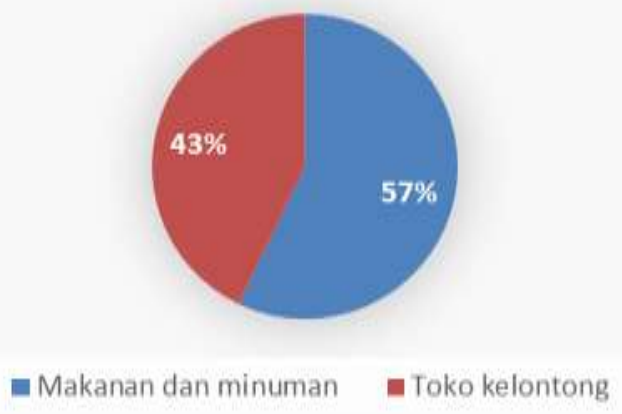

Gambar 4. Bidang usaha UMKM Desa Tanjungan

Tabel 2. Pendapatan usaha UMKM

\begin{tabular}{lll}
\hline No. & Pendapatan usaha & Besaran /bulan \\
\hline 1 & $<1$ juta & 2 \\
2 & 1,1 juta -2 juta & 3 \\
3 & 2, juta -3 juta & 2 \\
\hline & Jumlah & 7 \\
\hline
\end{tabular}

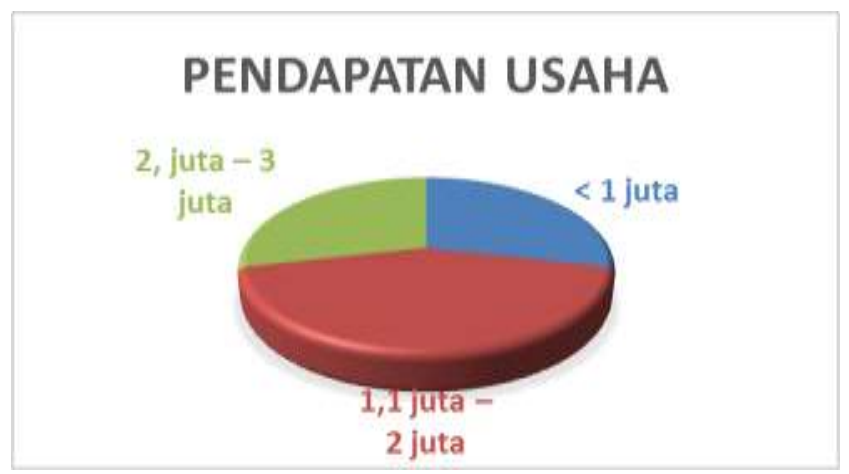

Gambar 5. Pendapatan Usaha UMKM

Respon terhadap pendapatan dan omzet UMKM selama 1 bulan dapat dilihat pada Tabel 2. Proses penyuluhan yang dilakukan di Desa Tanjungan mengenai sosialisasi pelatihan tentang cara pengelolaan keuangan dengan membuat laporan keuangan diberikan agar para pemilik UMKM dapat melakukan pengelolaan keuangan secara baik dan berimbang. 


\section{KESIMPULAN}

Dari hasil kegiatan di Desa Tanjungan, Kecamatan Driyorejo, Kabupaten Sidoarjo menunjukkan bahwa:

- Dengan adanya sosialisasi dan pelatihan ini maka diharapkan dapat membantu pemilik UMKM yang belum tau bagaimana cara membuat laporan keuangan yang baik menjadi bisa membuat laporan keuangan yang baik.

- Dengan adanya sosialisasi dan pelatihan ini, diharapkan pemilik UMKM bisa membuat laporan keuangan yang menjadi salah satu syarat pengajuan kredit di Bank untuk penambahan modal usaha.

- Dengan adanya sosialisasi dan pelatihan ini, para pemilik UMKM dapat lebih berkembang pada bisnis usaha yang dimiliki sehingga UMKM dapat berjalan sesuai harapannya semakin maju.

- Dengan adanya sosialisasi dan pelatihan untuk membuat laporan keuangan sehingga para UMKM dapat melihat jelas laporan keuangan yang telah disusun.

\section{UCAPAN TERIMA KASIH}

Ucapan terima kasih kami sampaikan kepada Bapak Rektor Universitas Maarif Hasyim Latif,, lembaga LPPM (lembaga Penelitian dan Pengabdian Masyarakat) UMAHA yang telah memfasilitasi program ini. Ucapan terima kasih kami sampaikan pula kepada Kepala Desa Tanjungan serta jajarannya dan masyarakat yang telah berpartisipasi aktif dengan semangat tinggi dalam kegiatan ini sehingga kegiatan pengabdian kepada masyarakat ini dapat berjalan dengan baik. Ucapan terima kasih juga teruntuk semua pihak semua yang membantu terlaksananya kegiatan ini.

\section{DAFTAR PUSTAKA}

Anggraini, D., \& Nasution, S. H. (2013). Peranan kredit usaha rakyat (KUR) bagi pengembangan UMKM di Kota Medan (studi kasus Bank BRI). Ekonomi Dan Keuangan, 1(3).

Narsa, I. M., Widodo, A., \& Kurnianto, S. (2012). Mengungkap kesiapan UMKM dalam implementasi standar akuntansi keuangan entitas tanpa akuntabilitas publik (PSAKETAP) untuk meningkatkan akses modal perbankan. Jurnal Ekonomi Dan Bisnis Airlangga (JEBA) | Journal of Economics and Business Airlangga, 22(3).

Suci, Y. R. (2017). Perkembangan UMKM (Usaha mikro kecil dan menengah) di Indonesia. Cano Ekonomos, 6(1), 51-58.

Sudaryanto, R., \& Wijayanti, R. R. (2013). Strategi pemberdayaan UMKM menghadapi pasar bebas Asean. Pusat Kebijakan Ekonomi Makro. Badan Kebijakan Fiskal. Kementerian Keuangan, Jakarta 


\section{(c) (i)}

(C) 2021 by authors. Content on this article is licensed under a Creative Commons Attribution 4.0 International license. (http://creativecommons.org/licenses/by/4.0/). 